\title{
Simulated impacts of weather variability on seasonally moving pastoral livestock in northern Senegal
}

\author{
Jarkko K. Niemi $^{1)}$, Kari Hyytiäinen ${ }^{2)}$, Astou Diao Camara ${ }^{3)}$, Cheickh Sadibou Fall ${ }^{3)}$ and Siwa Msangi ${ }^{4)}$ \\ ${ }^{1)}$ Natural Resources Institute Finland (Luke), Economics and Society, Seinäjoki, Finland \\ ${ }^{2)}$ University of Helsinki, Department of Economics and Management, Helsinki, Finland \\ ${ }^{3)}$ Institut Sénégalais de Recherches Agricoles, Dakar, Senegal \\ ${ }^{4)}$ International Food Policy Research Institute, Washington, USA
}

\begin{abstract}
Households in the arid or semi-arid regions often practice transhumance, which means that the household or part of it moves seasonally with animals from a common pasture to another. Semi-arid regions in the Sahel have faced increasing environmental pressure due to population growth and decreasing rainfall. In northern Senegal this has changed the pattern of movement and stocking densities in the area.

Pastoral livestock which utilizes common rangeland is heavily exposed to weather variability. The goal of this paper is to examine how potential changes in weather variability and rainfall could affect the decisions to move animals in an extensive pastoral livestock system across two regions.

Building on earlier research we develop a stochastic dynamic programming model that describes extensive, common-pasture-based livestock under stochastic and spatially varying weather. We extend previous research by allowing animal's movements between two regions and take into account that decisions can be adjusted when new information about the weather arrives. Decision rules to sell and move animals under exogenous price, market and climate scenarios are investigated.

The results show that in the absence of efficient feed markets and under unpredictable weather, transhumance can be a rational livestock management strategy. Weather has an important role in the herder's decision-making especially in years when the rainfall turns out to be below that of an average year. By contrast, economic variables play an important role when rainfall is not limiting herd sales decisions. Increased frequency of extreme weather conditions, such as heavy drought or rainfall, may have more severe impacts on livestock husbandry than gradual changes in the mean annual rainfall or temperature suggest. Hence, policies should aim at mitigating the negative consequences of extreme weather.
\end{abstract}

Key words: Weather variability, climate change, modeling, Senegal, resilience, livestock, transhumance 


\section{Introduction}

Pastoral livestock is dependent on weather. Households in the arid or semi-arid regions often practice transhumance, which means that the household or part of it moves seasonally with animals from a common pasture to another. This is common also in Ferlo, Senegal, which is part of the Sahelian rangeland, and where movements of pastoralists are driven by spatial distribution of annual rainfall. Semi-arid regions in the North Senegal region have over the past fifty decades faced increasing environmental pressure as population has more than tripled and the amount of rainfall has decreased (Ickowicz et al. 2012). These changes pose substantial challenges to extensive pastoral livestock management, which is a prevalent economic activity in the area. Livestock serves as an important source of food and cash for many households in the region. Due to increased demand for food and reduced productivity of rangeland, the competition on feed and rangeland has increased and longer distances are travelled nowadays than in the past to feed the animals (Cesaro et al. 2010).

Climate change can decrease the average annual rainfall and also increase the variability of weather, thus affecting the availability of vegetative biomass. For instance, McSweeney at al. (2010) projected that the rainfall in Senegal can decrease by approximately $3 \%$ per decade by 2060 . Moreover, the variability of rainfall has been estimated to increase by $30 \%$.

This paper captures the essence of a natural resources management problem that is fundamental to the extensive pastoralist's production strategy. The goal of this paper is to examine how potential changes in weather variability and rainfall could affect the decisions regarding the movement of animals within an extensive pastoral livestock system across two regions. Building on earlier research by Weikard and Hein (2011) we develop a stochastic dynamic programming model that describes extensive, common-pasturebased livestock under stochastic and spatially varying weather. We extend previous research - which focused on the stocking decision in a given pastoral area (Ferlo area in the North Senegal) - by allowing the animals to move between two regions and take into account that decisions can be adjusted when new information about the weather arrives. Decision rules to sell and move animals under exogenous price, market and climate scenarios are investigated. These scenarios can be regarded to address different price, market and climate change conditions.

\section{Material and methods}

\section{Objective function}

Dynamic programming was used to analyze the pastoral livestock manager's problem. Similar method was used by Weikard and Hein (2010). The objective function of the pastoral livestock manager is to maximize the value of livestock herd by adjusting stocking rate and the rate of transhumance (see Figure 1 for the description when each event takes place):

subject to: $\quad$ transition and biophysical Equations 2-6 and $V_{T}\left(\mathbf{S}_{\mathbf{t}}, \mathbf{m}_{\mathbf{T}}, \mathbf{r}_{\mathbf{T}}\right)$ are given.

where $V_{t}\left(\mathbf{S}_{\mathbf{t}}, \mathbf{m}_{\mathbf{t}}, \mathbf{r}_{\mathbf{t}}\right)$ is the maximized value of livestock herd at time period $t$ when the current stocking rate $\left.\left.{ }^{o}\right\}\right)$, carbon content of the soil $\left(\mathbf{m}_{\mathbf{t}}=\left\{m_{t}^{\text {Ferlo }}, m_{t}^{\text {Outside Ferlo }}\right\}\right)$ and the current year's rainfall Ferlo in the two regions indicated by the superscripts are given; $\left.h_{t}^{\text {move }}\right\}$ is the control vector which contains decisions to sell animals from the stock in Ferlo $\left(\mathrm{O}_{\mathrm{o}}^{\text {Ferlo }}\right)$ and outside Ferlo $\left(\mathrm{o}_{\mathrm{o}}^{\text {ooooooooooooo }}\right)$ and the decision to move seasonally with animals $\left(\mathrm{o}_{\mathrm{o}}^{\text {move }}\right.$, transhumance is indicated as the percentage of Ferlo's livestock that is participating in transhumance) as

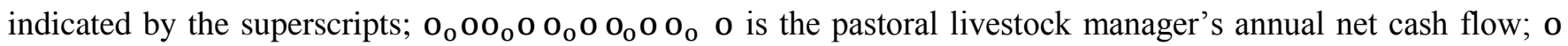
is the annual discount rate; $E$ is the expectations operator; and $T$ is the number of years examined. Transhumance directly affects soil carbon content in both regions and the amount of meat that can enter in the markets in the two regions, and it may affect the number of animals in stock in the Ferlo region and in region 'outside Ferlo'. During the dry season, transhumance increases competition on vegetative biomass 
outside Ferlo whereas in Ferlo the competition is reduced. Based on consultation with Ferlo herd owners, we assumed that maximum $90 \%$ of livestock population in Ferlo can move seasonally because people not moving with the animals may also need some livestock.

The pastoral livestock managers' annual profit, $\pi_{t}$ is determined by income from selling the animals minus variable costs of having the livestock and the costs of transhumance per TLU/ha (Tropical Livestock Units per hectare of land), and fixed annual costs.

\section{Transition equations and biophysical equations}

We model annual grass production (annual production of dry matter) as a function annual rainfall, which is a stochastic variable, rain-use efficiency of a semi-arid rangeland and carbon content of the soil. This approach is based on Weikard and Hein (2011), but their work has been expanded by taking into account the impact of soil carbon in increasing the retention of nutrients and water, and thus improving the plant productivity (see Bauer and Black 1994, Müller et al. 2012 for details).

Our model consists of four basic transition equations. The dynamics of soil organic matter are described for both regions separately. The dynamics are affected by the stocking rate (i.e. livestock population TLU per ha). The dynamics of the size of livestock population in both regions are described as a function of stocking rate, the sale of animals, and the reproduction rate of the animals. The dynamics are constrained by feed availability, as having too many animals relative to the amount of feed that is available will reduce the growth and viability of the livestock population (due to undernourishment and mortality).

A simulated year begins at the start of the rainy season. Transhumance begins at the end of the rainy season when a proportion of animals move from Ferlo to another region. These animals are assumed to return to their orgin by the end of the year, unless they are sold outside the Ferlo (Figure 1). During transhumance the relevant animal population will consume vegetative biomass available outside Ferlo, including high-quality agricultural byproducts sold for feed, and also their manure will remain there.

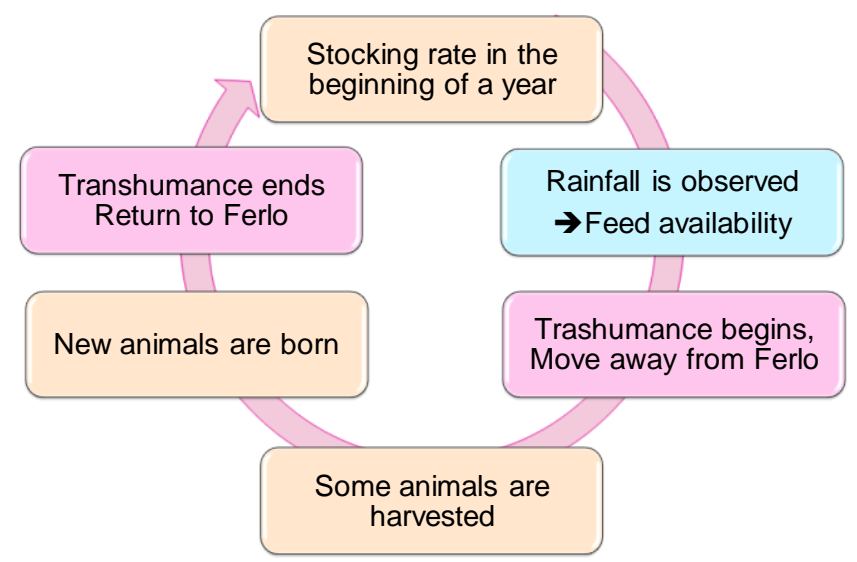

Figure 1. Description of the main events occurring in a pastoralist livestock her during a year..

\section{Data and scenarios}

Monthly statistics on rainfall (1950-2012) are available for Dahra observation station, which is located in the southern Ferlo region as well as for Kaffrine observation station. Kaffrine is assumed to represent region outside Ferlo, were used to simulate the rainfall. Most parameters used in the model were similar to Weikard and Hein (2011). The parameter values are available from the authors upon request.

Price information were obtained by interviewing livestock owners in the Ferlo region in December 2013 and by using information obtained from the statistics (CSA 2014). We use two meat prices, one for animals sold in Ferlo and another for the animals sold outside Ferlo. As opposed to Turner and Williams (2002), an analysis conducted with the FAO long-term price statistics and Senegalese weather data do not support the assumption that locally-observed drought would significantly affect meat prices in the region. Time horizon in the model was set at 30 years. 
The dynamic programming model was developed and solved in Matlab R2013a (8.1.0.604, Mathworks inc.) by using the value function iteration method (see e.g. Ljunqvist and Sargent 2000). The results are reported for low, medium or high rainfall years in the two study areas. A baseline simulation and five other scenarios reflecting climate change or increasing price levels were postulated and their impacts on the value function were simulated (see Table 1). Our analysis examined scenarios where one of the model parameters are adjusted from the baseline model while keeping other factors at the same level as in the baseline. The scenarios differ from the baseline scenario by adjusting the mean of rainfall, the standard deviation of rainfall, meat price, and the discount rate.

\section{Results}

Colors in Figure 2 illustrate the percentage change of the animal stock (i.e. newly born animals minus offtake divided by initial population) during one year period. The change is represented for different combinations of initial stocking rates in Ferlo and outside Ferlo (initial stocking rates measured in the beginning of rainy season), and for three rainfall scenarios.

The sustainability of current animal population in both the Ferlo and outside of the Ferlo depends upon the rainfall and stocking density in both regions because there is a movement of animals between the regions. In the event of an average rainfall year, Figure 2 shows that Ferlo (Figure 2c) can accommodate less animals (i.e. a lower stocking rate) than the region outside of the Ferlo (Figure 2d). Stocking rate also influences the offtake of animals. The larger stocking rate in the beginning of a year the more animals are removed from the stock during the year. The result is linked to the number of animals that one hectare of common pasture can feed. The rainfall impacts so that in a rainy year (e.g. Figure 2a) the stocking rate can increase during the year to a higher level than during a dry year (e.g. Figure 2e).

Figure 3 represents the economically sustainable stocking rates. The sustainable stocking rate in one region depends on the stocking rate in the other region. The higher is the stocking rate in one region, the lower it will be in the other region. However, rainfall also has a major impact on the optimal stocking rate.

Figure 4 describes the rate of transhumance (\% livestock population moving from Ferlo to outside Ferlo) by the stocking rate within the Ferlo and outside of the Ferlo. A higher proportion of the population is participating in transhumance in a dry year than in a rainy year. Stocking density outside Ferlo is also sensitive to the level of feed availability within the Ferlo when transhumance is possible. As herds which move between regions are competing for the same resources as pastoral livestock outside the Ferlo, the option to practice transhumance increases the stocking density within the Ferlo by a maximum level of 20\%, but decreases it outside Ferlo by a maximum level of 5\%. The option to practice transhumance was simulated to increase the value of livestock activity by approximately 5\%. Transhumance can act as a balancing factor and increase the aggregate stocking rate. However, the decrease in the stocking rate outside of the Ferlo depends upon the situation in Ferlo. If there is a large stock of animals in the Ferlo at the beginning of the year, the reduction in the stock outside Ferlo can be more dramatic than if there is a small level of stock in the Ferlo.

The rate of transhumance increases rapidly when the stock of animals in the Ferlo increases. However, when stocking rate outside of the Ferlo is large enough, there is more competition between animals for the available biomass and the rate of transhumance increases less rapidly when the stocking rate in Ferlo increases. Similar pattern can be observed also in cases where there is a lot of rainfall within the Ferlo.

The results show that in the absence of efficient feed markets and under unpredictable weather conditions, transhumance can be a rational livestock management strategy. Weather has an important role in herder's decision-making especially in years when the rainfall turns out to be below that of the average year. By contrast, economic variables play an important role when rainfall is not limiting herd sales decisions. Increased frequency of extreme weather conditions, such as heavy drought or rainfall, may have more severe impacts on livestock husbandry than gradual changes in the mean annual rainfall or temperature levels suggest. Hence, policies should aim towards mitigating the negative consequences of extreme weather. 
a) Low rainfall, \% sold in Ferlo

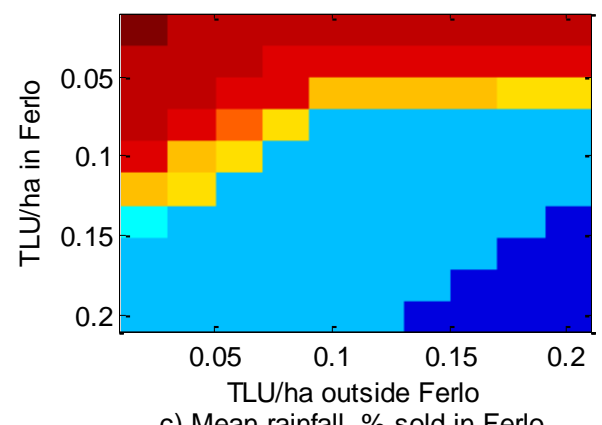

c) Mean rainfall, \% sold in Ferlo

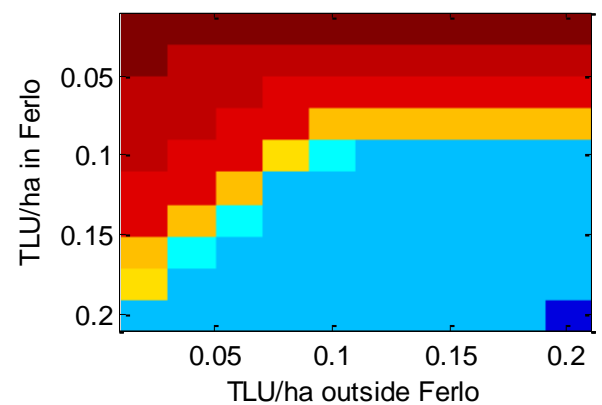

e) High rainfall, \% sold in Ferlo

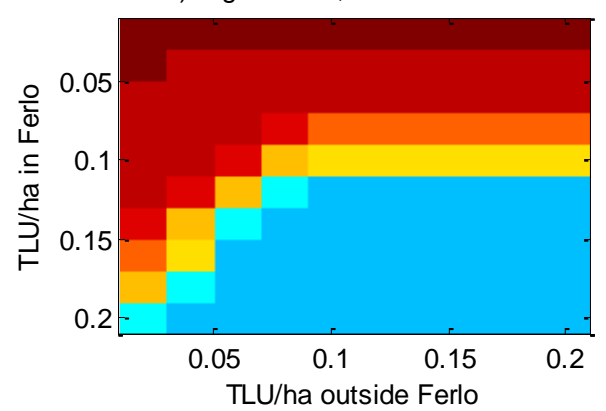

b) Low rainfall, \% sold outside Ferlo

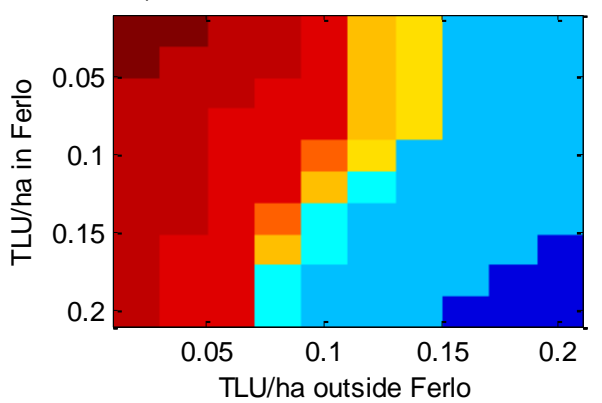

d) Mean rainfall, \% sold outside Ferlo

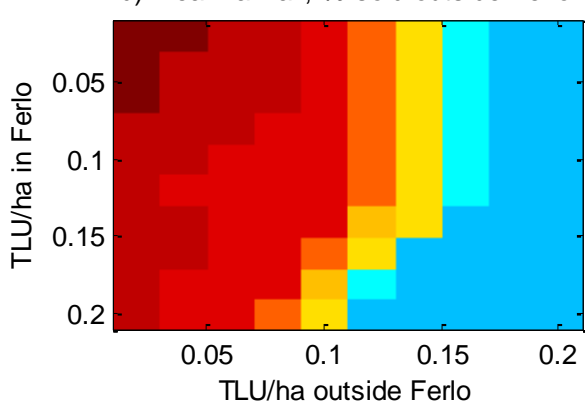

f) High rainfall, \% sold outside Ferlo

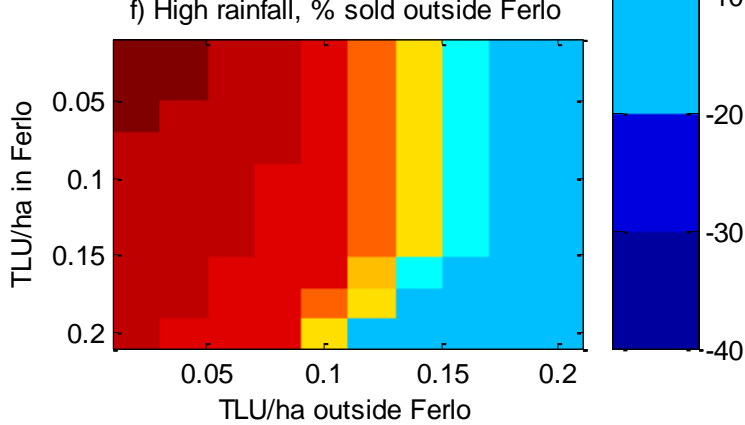

Figure 2. Change (\%, as indicated by the colors) in the stocking rate (TLU/ha, 0) in Ferlo (Figures a, c, e) and outside Ferlo $(b, d, f)$ for the low $(a, b)$, mean $(c, d)$ and high $(e, f)$ rainfall years, at different initial stocking rates in the respective regions in the beginning of the year.
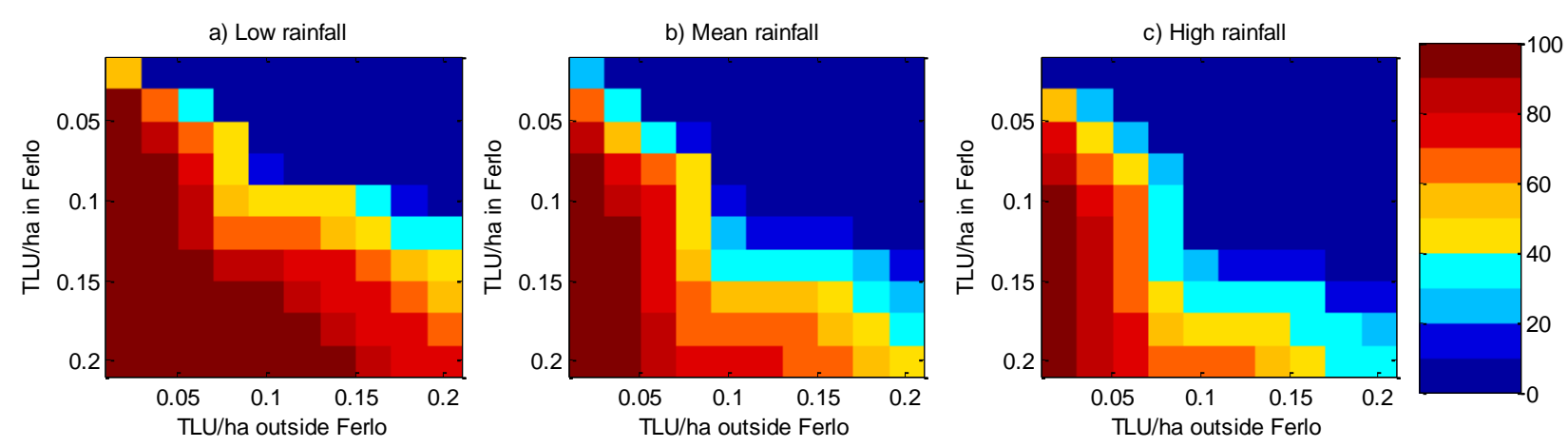

Figure 3. The rate of transhumance (0-100\% livestock population leaving from Ferlo as indicated by the colors) by the stocking rate (TLU/ha) in Ferlo and outside Ferlo in the beginning of the year (dark colors imply stronger reduction in the animal stock over a year) and for three rainfall year types (average, low, high rainfall). 

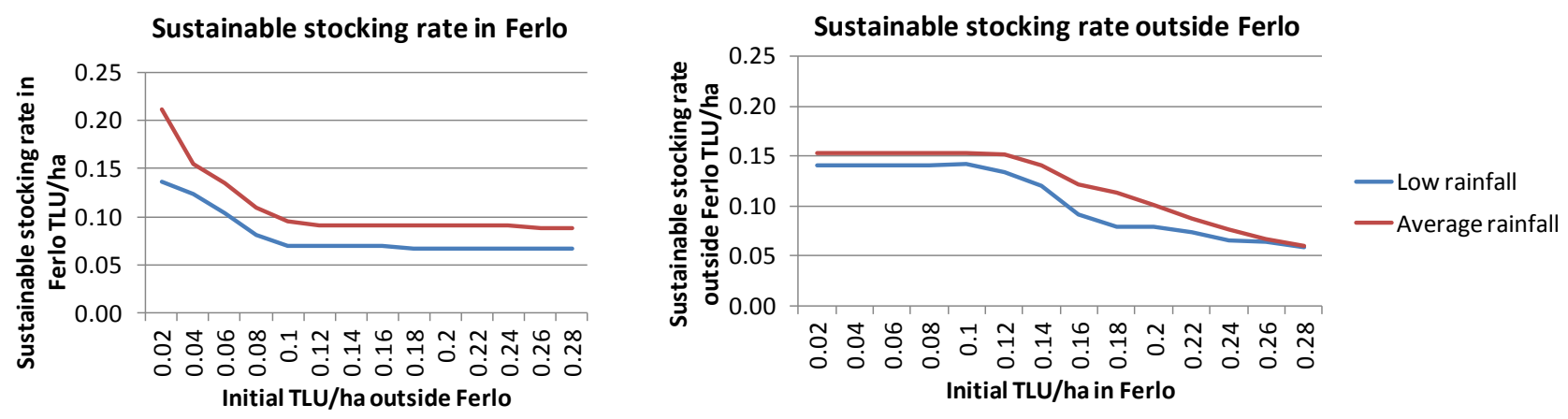

Figure 4. Economically sustainable stocking rate in Ferlo as a function of initial stocking rate in the region 'outside Ferlo' and annual rainfall (on the left), and economically sustainable stocking rate outside Ferlo as a function of initial stocking rate in the Ferlo region and annual rainfall (on the right).

Table 1. Change (\%) in value function when the baseline scenario and alternative scenarios are compared

\begin{tabular}{ll}
\hline Scenarios & $\begin{array}{c}\text { Percentage change in the } \\
\text { value function }\end{array}$ \\
\hline B Mean rainfall $-3 \%$ per decade & $-1 \%$ \\
C Standard deviation of rainfall $+30 \%$ & $-3 \%$ \\
E Meat price $+20 \%$ & $21 \%$ \\
G Meat price $-20 \%$ & $-21 \%$ \\
H Meat price $+2 \%$ per year & $21 \%$ \\
L Discount rate doubled & $-37 \%$ \\
\hline
\end{tabular}

1) Percentage change compared to the baseline scenario.

\section{Discussion}

Results suggest that the adjustments of animal stock size and transhumance are determined either by natural constraints (the availability of feed) or by economic decisions to maintain a stocking rate that his consistent with the levels of feed availability. Rainfall has a major impact on the optimal stocking rate and on the amount of livestock sold to the market. In the event of drought, more animals will be sold than in a normal year. In particular it affects the stocking rate in the Ferlo where water is the key limitation to the production of vegetative biomass. By contrast, when there is a plenty of rainfall, the availability of vegetative biomass may not be a limiting factor, and the animal stock is managed so as to maximize the value of the herd over a given time horizon.

Transhumance and stocking rates within the rainy region are buffers which are adjusted according to the levels of rainfall simulated within our model. In the absence of efficient feed markets, transhumance can be a rational way to adjust the livestock numbers to conform to varying weather conditions and biomass levels. It increases the possibilities of Ferlo's inhabitants to maintain their livestock at an acceptable level of productivity and health. However, it can increase stocking rate to a level which is not sustainable in some years. Results suggest that market conditions and time value of money (i.e. discount rate) can have a small impact on the optimal stocking rates and transhumance patterns. For instance, a larger discount rate can reduce animal stock levels and the present value of returns over the planning horizon.

Livestock managers in Ferlo could benefit from the option to purchase feeds from the markets instead of exclusively practicing transhumance. However, the uptake of purchased feeds is dependent upon the price (and the quality of the feed). Purchased feeds and transhumance are alternative options but are not mutually exclusive. Hence, transhumance is likely to continue although it could be carried out in a smaller scale -with some animals remaining in place with increased supplementation (i.e. for milk production), while others undertake transhumance to more humid regions. 


\section{Acknowledgements}

This publication is part of the FoodAfrica Programme, financed as a research collaboration between the MFA of Finland, Natural Resources Institute Finland, IFPRI, ILRI, ICRAF, Bioversity International, University of Helsinki and HAMK University of Applied Sciences.

\section{References}

Bauer, A. \& Black, A.L. 1994. Quantification of the Effect of Soil Organic Matter Content on Soil Productivity. Soil Science Society of America Journal 58, 185-193.

Cesaro, J.-D., Magrin, G. \& Ninot, O. 2010. Petit atlas de l'élevage au Sénégal. Commerce et territories. Publication du projet de recherché ATP ICARE. 36 p.

Ickowicz, A., Ancey, V., Corniaux, C., Duteurtre, G., Poccard-Chappuis, R., Touré, I., Vall, E. \& Wane, A. 2012. Crop-livestock production systems in the Sahel - increasing resilience for adaptation to climate change and preserving food security. p. 261-294 in: Meybeck, A., Lankoski, J., Redfern, S., Azzu, N., Gitz, V. (eds.). 2012. Building resilience for adaptation to climate change in the agriculture sector. Proceedings of a joint FAO/OECD workshop, 23-24 April 2012.

CSA 2014. Bulletins mensuels sur le suivi des marchés agricoles au Sénégal. Various issues. Commissariat à la Sécurité Alimentaire, Dakar. www.csa.sn

Ljunqvist, L. \& Sargent, T.J. 2000. Recursive Macroeconomic theory. MIT Press, Cambridge. 701 p.

McSweeney, C., New, M. \& Lizcano, G. 2010. UNDP Climate Change Country Profiles:

Senegal. http://ncsp.undp.org/sites/default/files/Senegal.oxford.report.pdf

Müller, J., Klaus, V.H., Kleinebecker, T., Prati, D., Hölzel, N. \& Fischer, M. 2012. Impact of Land-Use Intensity and Productivity on Bryophyte Diversity in Agricultural Grasslands. PLOSone 10.1371/journal.pone.0051520.

Turner, M. D. \& Williams, T.O. 2002. Livestock market dynamics and local vulnerabilities in the Sahel. World Development 30: 683-705.

Weikard, H.-P. \& Hein, L. 2011. Efficient versus sustainable livestock grazing in the Sahel. Journal of Agricultural Economics 62: 153-171. 